\title{
BENTUK PENYAJIAN LAGU OEMAR BAKRIE DI MARCHING BAND SWATAMI PADA GEBYAR PENDIDIKAN NASIONAL KABUPATEN LABUHANBATU UTARA
}

\author{
Utari Arsy Buana \\ Prodi Pendidikan Musik
}

\begin{abstract}
The results showed that one form of emotional expression that is channeled through the music and therefore, the group marching band Swatami on arranemen songs Oemar Bakrie brought by Marching band Swatami using three categories of instrument, namely: instrument Percussion in tone (Glockenspiel, vibraphone, Xylophone, Marimba), brass instruments (trumpet, Mellophone, Baritone, Tuba), and percussion (Senar drum, tenor drum, bass drum, cymbals). Choosing songs Omar bakrie for in the arrangements with the shape Marching band. Bakrie Oemar tempo songs using 163 has 51 bars and has two variations of the melody, the melody forms $A$ and B. Form benuk melodic presentation of the song sung by Oemar Bakrie Swatami Marching band is a form of self appreciation for issuing arts talent. Using costumes and makeup of their pride that seemed interesting and luxurious for a show. Using display / position players make this show the higher thevalue of his art.
\end{abstract}

Keywords: Forms of presentation, Song Oemar Bakie, Marching Band 


\section{PENDAHULUAN}

Musik merupakan seni yang menghasilkan suara terampil dan menyenangkan, untuk menggabungkan rangkaian musik dengan baik bahkan mempesona sehingga bunyi merdu akan dihasilkan sesuai dengan komposisi dan harmonisasi yang telah diatur sedemikian rupa. Musik terdiri dari harmoni, ritme, meter, nada, instrument dan suara. Kegiatan seni musik tidak hanya sekedar mendengarkan musik, namun juga dapat dilakukan dengan bernyanyi (vokal), memainkan alat musik (instrument), memainkan salah satu karya musik, memimpin kelompok musik (direksi), menciptakan sebuah karya musik, dan juga menganalisis karya musik. Marching band istilah dalam bahasa Inggris yang mengacu kepada sekelompok barisan orang yang memainkan satu atau beberapa lagu dengan menggunakan sejumlah kombinasi alat musik atau alat drum (alat band tiup, perkusi, dan sejumlah instrumen Percussion in Tone (PIT) secara bersama-sama. Penampilan marching band merupakan kombinasi dari permainan musik (tiup dan perkusi) serta aksi baris-berbaris dari pemainnya.

Lagu-lagu yang dibawakan dalam satu penampilan Marching band umumnya membawa satu ragam yang sama atau merupakan kombinasi atas beberapa ragam dalam satu tema yang sama, namun ragam yang dibawa dalam satu penampilan tiap-tiap Marching band bisa berbeda-beda. Secara struktural, umumnya karakteristik lagulagu yang dibawakan tiap-tiap Marching band memiliki tipikal elemen yang sama. Bagian "pembuka" yang ditujukan untuk mendapat perhatian penonton, "solo perkusi" atau disebut dengan feature, "balada" yang menampilkan solo musik tiup bersama dengan solo perkusi, dan "penutup" sebagai puncak dari penampilan. Di masing-masing elemen tersebut sering pula diwarnai dengan variasi teknik permainan, termasuk didalamnya permainan tempo, birama, yang ditujukan untuk mendapatkan satu dinamika permainan yang lebih seimbang dan sebagai wahana menunjukkan keterampilan grup.

Marching band Swara Taruna Melati adalah sebuah kegiatan ekstrakulikuler di Sekolah Menengah Atas Muhammadiyah 9 Kualuh Hulu. Berdiri pada Tahun 1994, sebelumnya bernama Drum Band Pemuda Muhammadiyah Kualuh Hulu. Pada Tahun 1997, Drum band Pemuda Muhammadiyah berubah nama menjadi Drum Band Ikatan Pelajar Muhammadiyah dan menjadi kegiatan Ekstrakulikuler Marching band. Sadar 
akan perkembangan Drum Band, pada tahun 2015 Drum Band Ikatan Pelajar Muhammadiyah SMA Muhammadiyah 9 Kualuh Hulu berubah nama menjadi Marching band Swara Taruna Melati. Dengan gaya show entertainment, MB Swatami merevolusi seluruh bagan penting yang terdapat di Marching band. Mulai dari merubah seluruh instrument sampai pola pelatihan dan show yang lebih menyajikan konsep yang apik dengan merepresentasikan lagu ataupun musik yang sudah diarangement sesuai dengan kebutuhan tema. Telah banyak prestasi yang didapat oleh MB Swatami baik secara kelompok maupun individual pemain, salah satunya, pernah menjadi juara umum pada Kejuaraan Marching band tingkat Kabupaten Labuhanbatu Utara dan juga terpilihnya salah satu pemain perkusi menjadi atlit Pra Pon 2016 cabang olahraga Drum Band.

Oemar Bakri awalnya adalah judul lagu ciptaan musisi legendaris Indonesia, Iwan Fals, yang populer tahun 1980an dalam album Sarjana Muda. Dalam penelitian ini, Angelo sebagai arranger mengkompos lagu Oemar Bakrie untuk kebutuhan marching band. Lagu ini disajikan dengan arransement baru. Hal tersebut yang membuat peneliti tertarik untuk meneliti masalah yang telah dikemukakan di atas dengan judul, "Bentuk Penyajian Lagu Oemar Bakrie di Marching Band Swatami Pada Gebyar Pendidikan Nasional Kabupaten Labuhanbatu Utara."

\section{TujuanPenelitian}

1. Untuk mengetahui penyajian lagu Oemar Bakri di Marching band Swatami.

2. Untuk mengetahui instrumen yang di gunakan dalam lagu Oemar Bakrie di Marching band Swatami

3. Untuk mengetahui bentuk lagu Oemar Bakri di Marching band Swatami.

\section{Landasan Teori}

Untuk membahas tentang bentuk penyajian lagu Oemar Bakrie di Marching Band Swatami pada Gebyar Pendidikan Nasional Kabupaten Labuhanbatu Utara penulis menggunakan beberapa teori yaitu Teori Bentuk Penyajian, Teori Musik, Teori Bentuk Lagu, Teori Marching Band

\section{Lokasi dan Waktu Penelitian}

Sesuai dengan judul penelitian (Bentuk Penyajian Lagu Oemar Bakrie di Marching Band Swatami pada Gebyar Pendidikan Nasional Kabupaten Labuhanbatu Utara ) maka lokasi penelitian ini dilaksanakan di lapangan sekolah Muhammadiyah 9 Kualah Hulu. Waktu yang digunakan dalam pelaksanaan penelitian ini Oktober 2015. 


\section{Populasi dan Sampel}

\section{Populasi}

Populasi dalam penelitian ini adalah seluruh pemain Marching Band Swatami, Pelatih Marching Band Swatami, penonton pada acara Gebyar Pendidikan Nasional

\section{Sampel}

Sampel nya adalah pemain Marching band Swatami, pelatih Marching band Swatami, Penonton

\section{Teknik Pengumpulan Data}

Teknik pengumpulan data yang dilakukan adalah sebagai berikut:

1. Observasi

2. Wawancara

3. Dokumentasi

4. StudiKepustakaan

\section{Teknik Analisis Data}

Dalam penelitian ini data yang digunakan adalah teknik analisis data kulitatif dimana proses mencari dan menyusun secara sistematis data-data yang diperoleh dari hasil wawancara, catatan lapangan, dan dokumentasi.

\section{ISI}

\section{A. Bentuk Penyajian Lagu Oemar} Bakrie di Marching Band Swatami pada Gebyar Pendidikan Nasional Kabupaten Labuhanbatu Utara

Sesuai dengan teori bahwa penyajian yaitu bagaimana kesenian itu di suguhkan kepada yang menyaksikan, penonton, para pengamat, pembaca, pendengar, khalayak ramai pada umumnya. Unsur unsur penunjang yang membantu bentuk itu dalam mencapai perwujudannya yang khas adalah: seniman, alat musik, kostum dan rias, lagu yang disajikan, tempat pertunjukan, waktu serta penonton". Sedangkan unsur yang berperan dalam penampilan atau penyajian adalah bakat, keterampilan, serta sarana atau media. Adapun penyajian lagu Oemar bakrie di Marching Band Swatami pada acara Gebyar Pendidikan Nasional adalah sebagai berikut.

Pertunjukan dilakukan pada acara Gebyar Pendidikan Nasional yang diadakan di halaman sekolah SMA Muhammdiyah 9 Kualuh Hulu pada tanggal 15 oktober 2015.

1. Kostum dan rias

Pemain Marching Band Swatami sudah siap melakukan pertunjukan yang spektakuler. Seluruh pemain sudah siap dengan kostum kebanggaan mereka dengan baju warna hijau kuning dengan motif songket melayu dan ditamah celana putih. Sedangkan Field Commander memakai pakaian bernuansa orange dengan topi bulu-bulu yang khas sebagai seorang Filed Commander gaun putih orange menambah pesona sebagai seorang Filed Commander yang cantik dan gagah, di tabah sarung tangun putih dan sepatu boot menambah ke anggunan sang Fieled Commander itulah kostum kebanggaan Marching Band Swatami. Dengan semangat yang membara tampak dari raut wajah pemain Marching 
band Swatami yang membawakan Lagu Oemar Bakrie dengan arransemen yang berbeda. Sebelum dimualai nya pertunjukan pelatih memberikan arahan terakhir sebelum tampil dan doa bersama agar hasil yang didapatkan maksimal.

\section{Pada saat pertunjukan}

Pada saat semua pemain sudah memasuki komposisi baisannya masingmasing Field Commander yang berada menghadap pemain membuat aba- aba agar setiap pemain bersedia memainkan alat instrumentnya. Barisan paling depan diisi dengan pemain instrument Percussion in Tone, di belakangnya diiisi dengan pemain Colour Guard, di sebelah kanan dan kiri sudah berbaris pemain instrument tiup, dan paling belakang ada pemain instrument perkusi. Setelah aba- aba dimulai pemain langsung memainkan alat instrumentnya di tambah dengan display yang sudah diarahkan oleh pelatih.

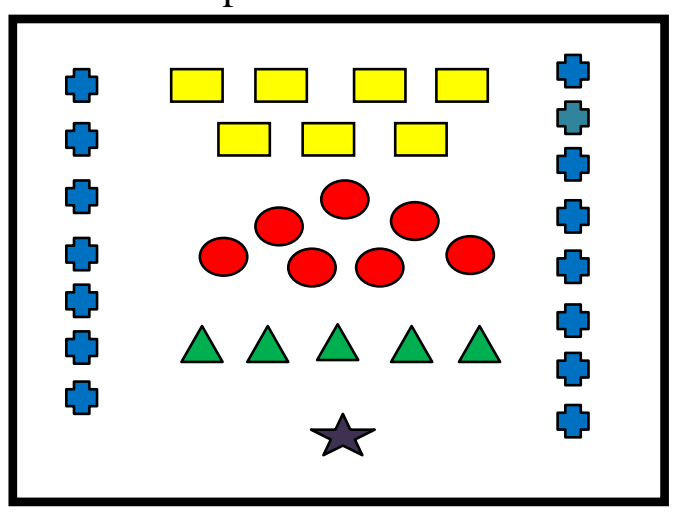

Posisi display pada saat awal pertunjukan

Keterangan :

= Pemain instrument tiup

= Pemain instrument perkus
= Pemain colour guard

$\triangle=$ Pemain percussion in tone (PIT)

$\hat{W}=$ Field Commander

Pada bagian awal lagu atau intro posisi pemain instrument tiup yang awalnya terbagi dua kanan dan kiri. Paling belakang ada pemain perkusi baris dua, di susul bagian depannya pemain colour guard membentuk pormasi bulat, di depannya pemain percussion in tone (PIT) sejajar rapi menghadap Field Commander.

Pada bagian song 1 atau melodi bentuk A posisi instrument tiup berubah kekiri dan pemain Colour guard pindah kekanan, jadi pada posisi ini instrument tiup dan instrument Colour guard sejajar menghadap kedepan. Semua pemain Marching Band melakukan gerakan kaki yang serentak dengan tumit kaki sedikit dijinjit ke atas, kecuali pemain Percussion in Tone (PIT) yang selalu berdiri tegak paling depan depan menhadap Field Commander. Terkesan rapi dan memiliki nilai pertunjukan seni yang sangat baik. Song 1 atau melodi bentuk A diulang dua kali lalu dilanjutkan dengan bentuk melodi B.

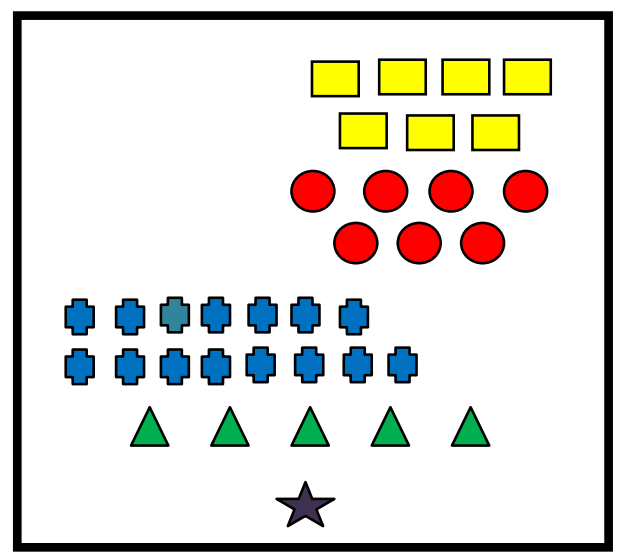


posisi display pada saat melodi A

Pada modulasi yang kedua pemain instrument tiup bergerak lambat kearah kanan dan pada instrument perkusi seluruh pemainnya bergerak ke arah kiri. Kemudian pemain colour guard berlari di sela-sela pemain instrument tiup dengan mengibarkan bendera merahnya.

Ada koreografi yang menarik pada bagian ini pada saat lagu Oemar Bakrie kepala seluruh pemain digelengkan kekanan dan kekiri menambah keriangan pada lagu ini. Pada saat itu juga pemain Colour Guard memutar-mutarkan bendera warna merah dengan semangat, sangat terasa sekali keriangan pada bagian ini. Setelah itu pemain instrument tiup lari-lari kecil membentuk sebuah lingkaran pada perpindahan bentuk variasi melodi dan rhytem dan saat itu juga pemain Colour Guard mengganti bendera dari warna merah kewarna biru sambil berlari kecil membentuk display.

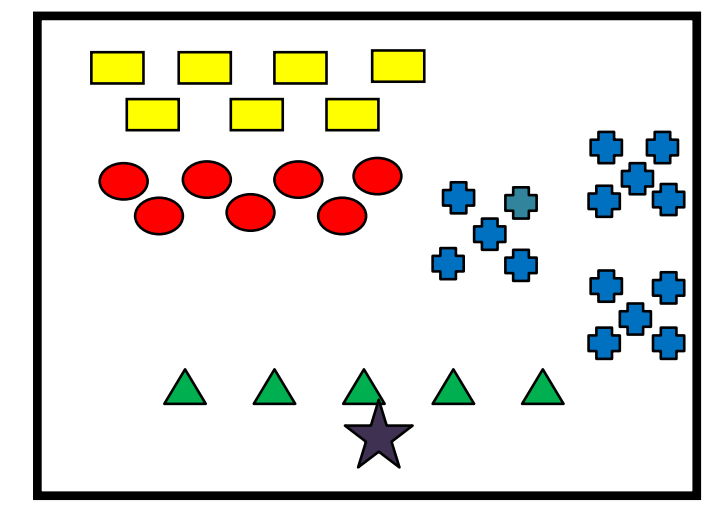

Posisi display pada saat melodi B

Pada Akhir bagian lagu pemain instrument tiup membuat dua barisan seperti segita setalah itu disusul dengan pemain instrument perkusi, dan barisan paling belakang ada pemain Colour Guard sambil memutar-mutarkan bendera warna biru. Dan tutup dengan aba-aba dari Field Commander.

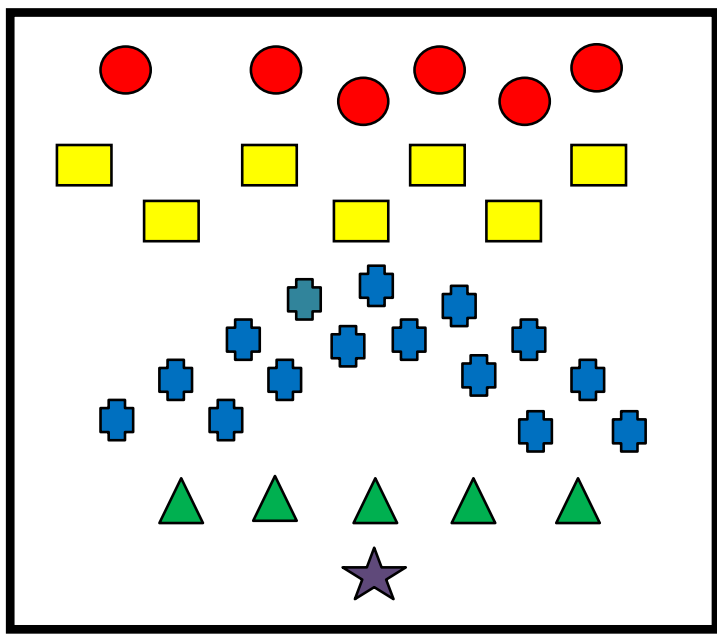

Posisi display pada saat akhir pertunjukan

B. Instrumen lagu Oemar Bakrie di Marching band Swatami

Marching band adalah kegiatan seni yang dalam kegiatannya melatih penggunaan kedua belahan otak. Belahan kanan maupun belahan kiri. Dari kegiatannya yang terbagi dua bagian tak terpisahkan yakni musical dan visual.

Instrumen yang digunakan dalam penampilan marching band umumnya dapat dikelompokkan pada beberapa kategori menurut jenis dan cara memainkan alat marching band. Pada arranement lagu Oemar Bakrie yang di bawakan oleh Marching Band Swatami menggunakan 3 katagori instrument yaitu : instrumen Percussion in tone 
(Glockenspiel, Vibraphone, Xylophone, Marimba), insrumen tiup (Terompet, Mellophone, Baritone, Tuba), dan perkusi ( Senar drum, Drum tenor, Drum bass, simbal). Setiap instrumen memiliki ciri khas bunyi nya masing - masing untuk membawa suasana yang hidup dan bergairah di lagu Oemar bakrie ini.

\section{Bentuk Lagu Oemar Bakrie di Marching Band Swatami}

Terbentukanya sebuah musik dihasilkan dari sebuah usaha untuk merekayasa bunyi. Bunyi yang dikelola menjadi musik akan membuat bahasa bahasa musik yang terbentuk dari alat alat musik yang dimainkan. Alat musik yang dimainkan memainkan peranannya masing - masing untuk menjadikan sebuah musik yang utuh.

Marching Band memiliki beberapa alat - alat instrument musik. Alat - alat musik instrument tersebut memiliki bentuk melodi dan bentuk ritme tersendiri dalam mengiringi komposisi Marching Band. Berikut adalah lagu Oemar Bakri yang di aranssemen ulang oleh Marching Band Swatami, yaitu :

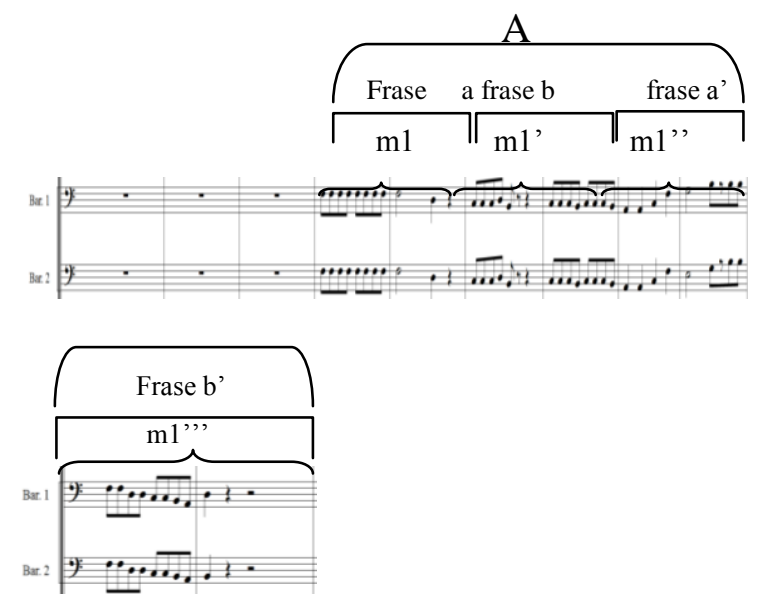

Keterangan:

A

Frase $\quad$ : Anak kalimat

M : Motif

Lagu Oemar Bakrie pada Marching Band Swatami melodi A menggunakan Instrument Baritone. Lagu pada bar 25-26 merupakan frase a yang terdapat motif 1, bar 27-28 merupakan frase b yang terdapt motif 1', bar 29-30 merupaka frase a' yang terdapat motif 1" dan pada bar 31-32 terdapat frase b' yang terdapat motif 1',' Dalam lagu Oemar bakrie yang di bawakan oleh Marching Band swatami ini bentuk melodi A diulang dua kali.

\section{PENUTUP}

\section{Kesimpulan}

\section{A. Kesimpulan}

Dari uraian-uraian tentang permasalahan dan pembahasan yang telah ditemukan pada bab-bab sebelumnya, maka pada bab ini penulis 
mencoba membuat kesimpulan mengenai bentuk penyajian lagu Oemar Bakrie di Marching Band Swatami pada Gebyar Pendidikan Nasional Kabupaten Labuhanbatu Utara sebagai berikut :

1. Bentuk penyajian lagu Oemar Bakrie yang dibawakan oleh Marching Band Swatami merupakan salah satu bentuk apresiasi diri untuk mengeluarkan bakat kesenian yang sangat berperan penting bagi aktivitas siswa/siswi SMA Muhammadiyah Kualuh Hulu. Menggunakan kostum dan riasan kebanggaan mereka yang terkesan menarik dan mewah untuk sebuah pertunjukan. Menggunakan display/ posisi para pemain membuat pertunjukan ini semakin tinggi nilai seninya.

2. Pada arranemen lagu Oemar Bakrie yang di bawakan oleh Marching Band Swatami menggunakan 3 katagori instrument yaitu : instrument Percussion In Tone (Glockenspiel, Vibraphone, Xylophone, Marimba), insrumen tiup (Terompet, Mellophone, Baritone, Tuba), dan perkusi
(Senar drum, Drum tenor, Drum bass, simbal). Setiap instrumen memiliki ciri khas bunyi nya masing - masing untuk membawa suasana yang hidup dan bergairah di lagu Oemar Bakrie ini.

3. Lagu Oemar Bakrie menjadi salah satu bentuk ungkapan emosional yang disalurkan melalui musik oleh sebab itu, group Marching band Swatami memilih lagu Omar bakrie untuk di arransemen ulang dengan bentuk Marching band. Peneliti akan meneliti Marching Band Swatami yang akan menyajikan lagu Oemar Bakrie dalam penampilanya. Lagu Oemar Bakrie menggunakan tempo 163 memiliki 51 bar dan memiliki 2 bentuk variasi melodi, yaitu bentuk melodi A dan benuk melodi $\mathrm{B}$.

\section{DAFTAR PUSTAKA}

A1.Sukohardi. 2012. "Teori musik Umum". Yogyakarta

Arikunto, Suharsimi. 2010. Prosedur Penelitian: Suatu Pendekatan Praktif. Jakrta: Bumi Aksara. 
Budilinggono. 1993. Bentuk Dan Analisis

Musik. Jakarta: Direktur Jendral Pendidikan Dasar dan Menengah Dapertemen Pendidikan dan Kebudayaan.

Djelantik, A.A.M. 2000. Estetika Sebuah Pengantar. Bandung: Masyarakat Seni Pertunjukan Indonesia.

Harapan. (2009). Keberadaan Musik Ilustrasi Sandiwara Di Radio RRI Medan. Medan : Skripsi untuk Mendapatkan Gelar Sarjana Pendidikan Universitas Negeri Medan.

Kirnadi. 2011. Dunia Marching Band. Jakarta: PT. Ekasatama Pertiwi.

Mack, Dieter. 2001. Pendidikan Musik: Antara Harapan Dan Realita. Bandung: Universitas Pendidikan Indonesia.

Maulima, Pasar. 2011. Metodologi Penelitian Pendidikan. Medan: Fakultas Matematika dan Ilmu Pengetahuan Alam Universitas Negeri Medan.

Sal Murgianto. 1983. "Metode, Teori, Teknik Penelitian Kebudayaan". Widyatama
Sharon Rose Pasaribu. (2014). Bentuk Penyajian Gondang Malim Pada Upacara Ritual Parmalim Si Inum Uras Di Kecamatan Pintu Pohan Meranti Kabupaten Toba Samosir. Medan : Skripsi untuk Mendapatkan Gelar Sarjana Pendidikan Universitas Negeri Medan.

Silitonga, Pita Hotma Dameria.2014. Teori Musik.Medan: Unimed Press

Sugiyono.2011. Metode Penelitian. Bandung: Alfabeta.

Prawika Lestari Purba.(2014).Kajian Bentuk dan makna lagu Juma Tidahan di Desa Sarimatondang Kecamatan Sidamanik Kabupaten Siamlungun. Medan : Skripsi untuk Mendapatkan elar Sarjana Pendidikan Universitas Negeri Medan.

Trianto.2011. Pengantar Penelitian Pendidikan Bagi Pengembangan Profesi Pendidikan dan Tenaga Kependidikan. Jakarta: Kencana Prenada Media Group.

Wais All Kornie Dikiana.(2015).Bentuk Penyajian dan Bentuk Musik dalam Mengarak Anak Berkhitan pada masyarakat Jawa di Desa 
Sukadamai Barat Kecamatan Pulau

Bandring. Medan : Skripsi untuk

Mendapatkan Gelar Sarjana

Pendidikan Universitas Negeri

Medan.

Yosef Sentosa. (2013).Keberadaan

Ekstrakulikuler Drumband di

Yayasan Pendidikan Nur Azizi

Tanjung Morawa Kabupaten Deli

Serdang.Medan : Skripsi untuk

Mendapatkan Gelar Sarjana

Pendidikan Universitas Negeri

Medan.

http//www.google.co.id/laboraturium+pdf

\&aqs 